\title{
The Relationship between Revenues Size and Actual Expenditures through the Closing Account Result of the Jordanian Government
}

\author{
Mohammad Ali Al Hayek ${ }^{1}$ \\ ${ }^{1}$ Accounting Department, Alal Bayt University, Jordan \\ Correspondence: Mohammad Ali Al Hayek, Accounting Department, Alal Bayt University, Jordan. E-mail: \\ mhayek30@yahoo.com
}

Received: November 21, 2017

Accepted: December 25, 2017

Online Published: January 15, 2018

doi:10.5539/ijbm.v13n2p40

URL: https://doi.org/10.5539/ijbm.v13n2p40

\begin{abstract}
The study aims to investigate the relationship between government revenue size and actual expenditure through the closing account result of the Jordanian government. To achieve this aim, the study performs an analytical study based on the descriptive analytical approach to identify the relationship between the revenues size and the actual expenditure through the closing account result of the Jordanian government. In doing so, the study relied on several scientific references related to the different variables of the study depending on the selected related literature and previous studies. Statistical methods were also used to analyze the data of the study in the form of actual data obtained from the general budget department and the related information published by the ministry of finance in Jordan (2007-2016). The results of the study indicated the finding of a statistical significant correlation between the revenues size variables and the total actual expenditure, from one side and the final government report (surplus, deficit) in Jordan, on the other side. There was also a reverse correlation between the actual revenues size and the size of foreign grants from one side and the final government report (surplus, deficit) in Jordan, on the other side. There was a positive and significant correlation between the current expenditure and the actual capital expenditure coming from the closing government account (surplus, deficit) in Jordan. The most significant recommendations suggested by the study are the need to develop and enhance internal and external auditing of the collected revenue dues using effective methods; working on listing all incoming foreign grants in the general budget to be subjected for auditing, developing, increasing internal, external auditing on the current expenditure waste, and feasibility of the capital expenditure.
\end{abstract}

Keywords: General budget, closing account, Actual revenues, Actual expenditure, closing account result

\section{Introduction}

Government general budget consider very importance part in the government accounting system, considering the size of this budget, the method of covering the various revenues items of the expected revenue within the budget's fiscal year. Monitoring the implementation of budget during the fiscal period by recording, determining, and logging until preparing the final report or closing account at the end of the fiscal year, which is considered actual assessment of the government's performance in the fiscal year (surplus, deficit), is an essential part of auditing activities. Decreasing the size of fiscal deficit is one of the major problems facing the Jordanian consecutive governments; leading to major community debate.

The Jordanian governments have been seeking to decrease the deficit by adopting various methods, which aims to increase the domestic revenues by raising taxes and fees, improving taxes and fees collection procedures, obtaining domestic and foreign loans, seeking to obtain grants and aids, control government expenditures using downsizing, and mentoring mechanisms on the implementation of general budget. In addition to the adopting results, oriented budget approach in an attempt to improve the infrastructure and complete several domestic projects to achieve sustainable community development. This study is an attempt to identify the relationship between the variables of actual revenues and expenditures in the form of domestic revenues, foreign grants, current expenditures, and capital expenditures by calculating the final report of the state (surplus, deficit).

\subsection{Problem of the Study}

From a government accounting perspective, the closing account or final report list is considers one of the tools to monitor and supervise the implementation of the government public budget. It is one form of annual report that 
reflects the accrual expenditures and revenues during the fiscal year, and calculates the resulting surplus and deficit in the budget. The final report assesses the government's achievement in obtaining its well-defined objectives and its ability to monitor the implementation of the general budget. Nevertheless, the problem of sustaining deficit year after year is one of the major problems facing the Jordanian government, which led to their attempts to reduce such deficit by adopting various financial policies that aims to increase revenues and control expenditures. Specifically, the problem of this study may be summarized in this main question:"Is there a statistical significant relationship between the revenues size and the actual expenditures through the closing account result of the Jordanian government?" From this main question, the following questions were emerged:

- Is there a relationship between the domestic revenues size and the closing account of the Jordanian government?

- Is there a relationship between the foreign grants size and the closing account of the Jordanian government?

- Is there a relationship between the current expenditures size and the closing account of the Jordanian government?

- Is there a relationship between the capital expenditures size and the closing account of the Jordanian government?

\subsection{Importance of the Study}

The government general budget has a great significance in the public accounting system as it defines the size of budget, the method to cover the items of various revenues and the expected expenditures in the yearly fiscal budget, the implementation procedures, the control mechanisms, the achievement of budget objectives by preparing the final report, and the resulting actual surplus and deficit. The financial deficit is one of the major problems facing the Jordanian government as it has become a challenge for the successive Jordanian governments, which sheds light on the significance of this study as it attempts to identify the relationship between the revenues elements related variables and the actual expenditure variables represented by the domestic revenues, the foreign grants, the current expenditures, and the capital expenditures through the closing account result of the Jordanian government (surplus, deficit).

\subsection{Objective of the Study}

Generally speaking, the study sought to identify the relationship between the revenues and the actual expenditures size through the closing account of the Jordanian government. More specifically, the study is out to achieve the following objectives:

- Identify the relationship between the domestic revenues size and the closing account result of the Jordanian government.

- Examine the relationship between the foreign grants size and the closing account of the Jordanian government.

- Examine the relationship between the current expenditures size and the closing account of the Jordanian government.

- Study the relationship between the capital expenditures size and the closing account of the Jordanian government.

\subsection{Hypotheses of the Study}

The following main hypothesis guided the design of the study, which stated: "There is no statistical significant relationship between the revenues size and the actual expenditures through the closing account result. From this main hypothesis, the following hypotheses were derived:

H1- There is no statistical significant relationship between the domestic revenues size and the closing account of the Jordanian government.

$\mathrm{H} 2-$ There is no statistical significant relationship between the foreign grants size and the closing account of the Jordanian government.

H3- There is no statistical significant relationship between the current expenditures size and the closing account of the Jordanian government.

H4- There is no statistical significant relationship between the capital expenditures size and the closing account of the Jordanian government.

1.5 Previous of the Study

- Nazim, Ullah (2016), "The relationship of government revenues and government expenditures: a case study of 


\section{Malaysia"}

The main objective of the study was to identify the relationship between the government expenditures and revenues, the increase of total GDP in Malaysia and its relationship with the government revenues and expenditures (2002-2013). The data related to the Malaysian government revenues and expenditures were obtained from the Malaysian government website, the Nigara Malaysian banks, and the Malaysian ministry of finance. The descriptive analytical design was used to identify the relationship between the revenues and expenditures variables (2002-2013). The results of the study indicated a statistical significant relationship the between revenues and expenditures. Despite the fact that the majority of the government revenues were direct taxes, the government expenditures varies only due to the changes in indirect taxes and the non-taxes revenues. Furthermore, there was a statistical significant and positive effect on GDP in Malaysia, indicating at the same time that Malaysia is an Islamic country facing budget deficit since 1998.

- Al Daoud, Yazan Mohammad Khair (2016), "The Role of Auditing and Monitoring of the Jordanian Auditing Bureau in controlling the Jordanian General Budget (2004-2014)":

The study aims to examine the actual and estimated revenues and expenditures in the final reports in the genera budget law and to identify the role of auditing bureau in controlling these expenditures. The study made use of the descriptive analytical design by using the data and statistics concerning the variables of the study. Two sample t- tests, means, and standard deviations were used in data analysis. The results didn't indicate any statistical significant differences between the estimated and actual values of the general revenues and expenditures and grants. There were statistical significant differences between the estimated and actual financing budget.

- RiteshKalra, and Tejaswini (2015), "A Comparative Study of Budgeted Expenditure and Actual Expenditure in Relation to Haryana Budget":

The study aims to identify the efficiency of Haryana budget with respect to controlling expenditures and to compare the current and capital expenditures and revenues listed in the budget with the actual expenditures in the Haryana budget. Data available for a time period of eight years (2006-2013) were obtained from the website of ministry of finance in Haryana Region- India. Several statistical measures (means, standard deviations, two sample t- tests) were used to analyze data obtained. The results of the study didn't show any statistical significant differences between the listed expenditures in the budget and the actual expenditures (current, capital).

- Nemanja, Lojanica (2015), "Government Expenditure and Government Revenue - The Causality on the Example of the Republic of Serbia":

The purpose of the study was to examine the relationship between government revenues and expenditures in Serbia (2003-2014) to show the necessary procedures needed to decrease deficit in the Serbian government budget. For data analysis, autoregressive distributed lag (ARDL) was used, while the Granger causality has been tested within the vector error correction model (VECM).The empirical results obtained in this work represented in testing the stationary through the (ADF) and KPSS tests, and found that the government revenues and the government expenditures are not stationary after the second difference. Namely, they aren't in line with the integration (2). Further analysis has revealed a counteraction between the variables. Also, the analysis has shown that, in the long run, there is a non-directional causality moving from government expenditures towards government revenues.

- Al Hayek, et al. (2014), "The Effect of Jordanian General Budget Size on the Auditing Outcomes Size in Jordanian Auditing Bureau":

The study aimed to examine the effect of Jordanian general budget size on the size of auditing outcomes issued by the Jordanian auditing bureau. To achieve this objective, the study adopted a descriptive analytical design based on the analysis of the variables to determine the effect of the Jordanian general budget on the size of auditing outcomes issued by the auditing bureau. In doing so, data from the general budget department and the auditing bureau (2007-2010) were analyzed. The results of the study didn't indicate any statistical significant relationship between the Jordanian total general budget size and the general current expenditure size, general budget size for the individual government departments, expenditures size for the individual government departments, capital expenditures size for the individual government departments from one hand, and auditing outcomes size in the auditing bureau, on the other hand. The results of the study indicated a statistical significant relationship between the capital expenditures size in the general budget and the auditing outcomes in the auditing bureau.

- Al Edwan, Khalid Issa; Al Sharaa', Mohammad Kanoush (2014), "The Political Dimensions of the Government 


\section{General Budget":}

The study investigated the dimensions of the government general budget from a political perspective as it examined the political importance of legislative bodies' address of the government general budget without ignoring the technical aspects of the budget. To achieve the objectives of the study, the organizational and analytical approaches were employed. The results of the study indicated that the government general budget includes several political dimensions in addition to its technical, legislative, and financial dimensions, and the most important political dimensions that the legislative institutions relies on when handling the general budget is to gain approval on this budget, and is politically escalated to withdraw confidence in the government, as the general budget is a political mirror that reflect the balance of powers between the legislative institutions and the government. There is also a role for the government's political regime in determining the political dimensions of the general budget.

- Damian C. Nwosu and Harrison O. Okafor (2014), "Government revenues and expenditures in Nigeria: A disaggregated analysis":

The study examined the relationship between current and capital government expenditures and the total oil and non-oil revenues in Nigeria using time series (1970- 2011). The study utilized co-integration techniques and (VAR) models which included an error correction mechanism (ECM) as the methods of analyses. The results of the study showed a long term balances relationships between government expenditures and revenues. Furthermore, a statistical significant relationship was found between the recurrent expenditure and oil, and the non-oil revenues. The results support the assumption of expenditures in Nigeria and the increase in government expenditures without an equal increase in revenues will increases the risk of budget deficit.

- Mohsen Mehrara; Abbas Ali Rezaei (2014), "The Relationship between Government Revenue and Government Expenditure in Iran":

The study investigated the relationship between government revenues and expenditure in Iran using the annual data obtained from the Iranian Central Bank (1978-2011) as the study performed time series analysis to analyze data characteristics using unit root tests (ADF) and Zivot-Andrews unit root test, which indicated that the series are (1). The Toda-Yamamoto Granger causality test found non-directional causality running from government revenues to government expenditures, and these results are consistent with the revenue-spend hypothesis.

- FarshadSameniKeivani (2013), "The Relationship between the Government Expenditures and Revenues in the Long Run: A Case Study of Iran":

The study investigated the relationship between the current government's expenditure and the long term oil and taxes revenues in Iran. To achieve the objective of the study, time series financial data (1986-2011) obtained from the Iranian central bank website were employed. The analytical descriptive design used the data and statistics related to the variables of the study and were analyzed via EVIEWS and SPSS software. The results of the study showed a statistical significant relationship between the oil revenues and government long term expenditures. It was found that oil revenues represent one of the major variables affecting government decisions to determine the current expenditures rate.

- Joseph ChukwudiOdionye, Uma, KaluEbi (2013), "The Relationship between budget deficit and interest rate: evidence from Nigeria":

The study investigated the relationship between budget deficit and long term interest rate in Nigeria (1970-2010) using the Vector error correction model (VECM). The results of the study showed a long term relationship and a positive effect for deficit and interest rate, which means any increases in government deficit leads to increase in interest rate.

- Abdulla S. Al-Khulaifi (2012), "The Relationship between Government Revenues and Expenditures in Qatar: A Co-integration and Causality Investigation":

The objective of the study was to examine the relationship between government revenues and expenditures in Qatar. To achieve this objective, annual financial statement (1980-2011) were analyzed using the different descriptive statistics to examine the relationship between the variables investigated. The results of the study showed a one direct causal relationship between the government revenues and expenditures in Qatar.

- SaeedKarimiPetanlar, SomayeSadeghi (2012), "Relationship between Government Spending and Revenue: Evidence from Oil Exporting Countries":

The study examined the relationship between government long term expenditures and revenues in oil exporting countries (2000-2009) using PVAR framework. The main focus of the study was on oil revenues, which take the 
lion's share in the revenues size in these countries. The results of the study showed a statistical significant relationship between oil revenues in these countries and the government expenditures size. Furthermore, the study showed that the increase of $(1 \%)$ in the oil revenues leads to an increase of $(1.16 \%)$ in the government expenditures.

- Al Louzi, Suleiman Ahmad \& Abu Al Sundous, Jihad Ahmad (2001), "Analyzing the gap between the estimated general budget and the actual budget in the Hashemite kingdom of Jordan (1996-2006)":

The objective of the study was to examine the relationship between the estimated revenues and expenditures and the actual revenues and expenditures in the Jordanian general budget (1996-2006), to identify the variation between them, the cause of these deviances, and the procedure taken to reduce them in accordance with the government general financial policy. To achieve the objectives of the study, a descriptive design was adopted which includes the means and the standard deviations. Figures and illustrations were also employed to test the hypotheses of the study. The results of the study indicated no statistical significant variations between the estimated revenues and the actual expenditures. Nonetheless, there was a statistical significant difference between the estimated and actual expenditures size. Finally, there was statistical significant difference between the actual revenues and the actual expenditures.

\subsubsection{Previous Studies Summary}

This study benefits from the previous studies in enriching and covering the theoretical aspects of the study, and to make use of information presented in the previous studies to develop the study design. Despite the importance of research and previous studies and according to the researcher's limited knowledge, the previous studies only addressed the economic dimension of the estimated budget and reasons for the deficit in the general budget. What makes this study unique, it's one of the first studies that cover the Jordanian environment and it aims to investigate the relationship between the actual revenues and expenditures using the final report or closing account of the Jordanian government. It used the analytical descriptive method to determine the nature of the relationship between the variables examined. In doing so, the study relied on the data available from the general budget department in Jordan and the reports provided by the Jordanian ministry of finance (2007-2016), where the closing account of the Jordanian government gets great attention of the government accounting system, through selection and recording of the actual government expenditures and revenues, during the financial period, reaching to prepare the closing report list, which represents the end result of the public accounting activities. Therefore, the topic deserves more examination and farther researches to identify all the aspects related.

\section{Literature Review}

The following are a review of the previous literatures related to the variables examined in this study, this includes:

\subsection{Government General Budget}

The government general budget is one of the accounting tools used to plan the government revenues for a specific future fiscal period. It is considered as a general law which gets approved by the legislative authority represented by the parliament. Therefore, the government general budget depends mainly on estimation and approval. The government general budget in Jordan passes through several important steps; the first phase is the preparation of the general government budget by coordinating with other government bodies to prepare the blueprints of the proposed budget. In the second phase, the budget will be given to a consulting team consisting of several experts in budgetary issues to discuss it. Third, the proposed budget passed to the board of cabinets to approve it, as the future general budget law requires it to be passed to the parliament (approval phase). The final phase represents the starting point of the implementation, as the assessment and monitoring phase. The general government budget is prepared using several methods and procedures, such as items budgeting, programs and performance budgeting, planning and programming budgeting, and zero based budgeting. The Jordanian general budget is prepared using items budgeting based on the administrative and qualitative index. Furthermore, the Jordanian government adopts the results-oriented budget to improve the infrastructure, to complete several projects contributing to the society's welfare, to achieve the concept of sustainable development, and to provide continuous services (Jordanian Department of General budget, 2017). The government general budget is strongly connected with the government accounting system, where it provides the budget developers with historical data related to expenditures, revenues, and the mechanisms used to calculate the government future budget estimations. The financial reports (the outcomes of the government accounting system) considers one of the effective tools to deliver information and provide it to whoever needs it for various purposes, through classifying it or recording it in the suitable accounts. The most important financial reports developed based on 
the financial system instructions (No.3), 1994, are the final report list and the monetary center list.

\subsection{Government Closing Account List}

It is one of the financial list equivalents to the income list found in other forms of accounting, at the end of the fiscal period. Nonetheless, government accounting doesn't aim to gain profits, where the government closing account list marked the revenues accounts actually collected and the expenditures being spend ( the monetary base) within the fiscal period and identify the final and closing fiscal result ( surplus/ deficit).The government closing account differs from the general budget, as the latter is actual estimation and expected figures for the future fiscal year, while the earlier is actual figures for the revenues being collected, and the expenses paid within the terminated fiscal year. Also, the general budget is issued based on a legislative law while the closing account doesn't need such legal procedures and only needs to be delivered to the legislative authority for monitoring purposes and the assessment of the executive authority (the government). The general budget is prepared by the general budget department, while the government closing account is prepared by a team of experts in the Jordanian ministry of finance (Jordanian Department of General budget, 2017).

\subsection{Actual Revenues}

These are all the funds collected within the fiscal time period. It's the direct and indirect taxes, the rents, and fees and fines imposed by the government according to the legislations due, in addition to the natural resources that provide income for the government. All the collected revenues are deposited in the general treasury. Government departments and other governmental bodies are prohibited to maintain each of these revenues according to the government financial system no. (3), 1994. These revenues are collected in cash or by certified checks or financial transactions.Revenues are considered one of the main pillars in government financial management and the executive governmental program consider as tool that assist the government to achieve its goals. The taxation revenues are the most important revenues source in Jordan (Jordanian Department of General budget, 2017).

\subsection{Foreign Grants}

These are actually foreign aides provided by the rich countries, who have strong economic systems to the developing countries who suffer from deficits in their budgets. These take the form of grants, which their expenditures confined in specific fields or programs.

\subsection{Actual Expenditures}

Actual expenditures are the money spent according to the financial allocations listed in the government general budget which are divided and allocated based on the current or capital expenditure supported by documents provided that they don't violate the applied legislations. Financial system number (3), (1994), prohibits allowing any expenses or recording them in the official records, unless the services have been performed or the tasks have been completed or the goods have been delivered to the warehouses, except for some cases such as loans and advanced deposits based on the nature of the contract and agreements signed between the parties. The actual expenditure figures in Jordan indicate a noticeable increase in the public expenditures. The current expenditure figures have increased significantly on the expense of capital expenditures (Jordanian Department of General budget, 2017).

\subsection{Surplus/ Deficit}

These are the differences between the revenues and expenditures. In this case, the revenues exceed the expenditures; this is the case of surplus, while deficit means that expenditures exceed revenues. In the government general budget, the surpluses or deficits aren't actual and estimated. In most cases, the deficit is called intentional deficit (FarshadSameniKeivani, 2013), where some countries tend to increase the budgetary deficit to increase or stimulate revenues collection process, to reduce expenditure, and obtain grants and loans. As for the result of the government closing account list, it is either actual surplus/ deficit resulting from the actual differences between actual revenues and expenditures, and show the government ability and efficiency in executing the general budget. The increase in deficits is attributed to various economic, social, supervisory, and political reasons, such as lack of government expenditures reduction, the weak levy, fiscal evasion, the huge size of public bodies, and the escalating levels of corruption. The government accounting system assumes a significant role in monitoring these reasons by using effective monitoring systems on expenditures, improving government levy, reducing fiscal evasion, and more importantly; reducing corruption by recording, classifying all the public transactions, summarizing the financial processes related to the government activities, developing financial list, and the monetary government position at the end of the fiscal year. 


\section{Methods and Procedures}

\subsection{Population and Sample of the Study}

To achieve the objectives of the study, and to test hypotheses, the study used the actual data obtained from the final reports/ closing account of the Jordanian general budget for the years (2007-2016).

\subsection{Variables of the Study}

To achieve the objectives and to test the validity of the study hypotheses, the variables of the study were classified as follows:

-Independent variables: Domestic revenues, foreign grants and current expenditures, capital expenditures.

-Dependent variable: The result of the final financial report (surplus/ deficit).

\section{Study Methodology}

The study employed the analytical descriptive method by analyzing the relationship between each of the individual items in the government final financial report which represented by the actual expenditures and revenues in the result of the final financial report. This was achieved by relying on the necessary scientific references (previous literatures and studies) and by examining the various aspects of variables included in the study. Provides the researcher with the opportunity to be well- informed about the various aspects of the problem examined and to build a solid theoretical foundation to complete the research study. Furthermore, statistical methods were used to analyze the study data by relying on the information available in the Jordanian department of general budget and the Jordanian ministry of finance for the period (2007-2016). The practical aspects of this study included three basic dimensions:

First Dimension: Its related to the validity of the data obtained for statistical analysis to figure out whether the analyzed data are close to the normal distribution, if not, then, the necessary statistical methods performed to enable the researcher from testing the study hypotheses appropriately. In order to do that, the multi-co linearity test, Autocorrelation test, and Hetroskedasticity test were all used.

Second Dimension: It's related to the descriptive statistics of the study variables, by using the various descriptive statistics measurements, such as mean, standard deviation, and median for the biggest and smallest values were calculated to describe the study variables to reflect the status of the data obtained.

Third Dimension: It's related to the study hypotheses test and parameters calculation of the multiple regression analyses.

\subsection{Statistical Analysis}

The study employed e-views statistical software to perform the suitable statistical analysis to accept or reject the study hypotheses, at the significance level of $(0.05>$ a $)$ using the following statistical tests:

- Normal distribution test: to identify if the data obtained were normally distributed or not. For this objective, Jarque-Bera test was used and the rule of this test is that the data are normally distributed if the statistical significance of Jarque-Bera test was greater than $(0.05>a)$.

- Multi-co-linearity test: for the study model as co-linearity diagnostics measure by calculating the tolerance coefficient for each of the independent variables and then computing the variance inflation factor (VIF) coefficient.

- Autocorrelation test: to verify the absence of autocorrelation problem by performing the Durbin Watson test to validate this assumption.

- Hetroskedasticity test: to verify the absence of standard measurement error variance in the study model, and identify this problem and solve it, by adopting the white test.

- Descriptive Statistical Techniques: to describe the study variables, by calculating means, standard deviations, biggest, and smallest values.

- Time Series Data (2007-2016): These data are cross section and for this reason, Pooled Data Regression was employed.

\subsection{Testing the Validity of Data For Analysis}

Before performing the data analysis and testing hypotheses, there is a need first to identify data characteristics to test their validity for use in testing the hypotheses. This was achieved using the following tests: 
Table 1.

\begin{tabular}{lllllll}
\hline & \multicolumn{2}{l}{ Normal-Distribution } & \multicolumn{2}{l}{ Time Series } & \multicolumn{2}{l}{ Multicollinearity } \\
\cline { 2 - 6 } Variables & \multicolumn{2}{l}{ Jarque-Bera Test } & \multicolumn{2}{l}{ Stationarity } & \multicolumn{2}{l}{ Collinearity Statistics } \\
& J-B & Prob. & PP & ADF & VIF & Tolerance \\
\hline Actual domestic revenue & 0.932 & 0.627 & -15.9 & -6.9 & 4.653 & 0.215 \\
Actual External grants & 0.856 & 0.652 & -6.3 & -4.0 & 1.660 & 0.602 \\
Current Expenditure & 0.887 & 0.642 & -6.6 & -6.9 & 4.237 & 0.231 \\
Capital Expenditure & 0.499 & 0.779 & -5.9 & -6.2 & 1.193 & 0.838 \\
Autocorrelation Test & Durbin Watson Test & 2.371 & & & \\
Heteroskedasticity Test & White Test(Sig.) & 0.034 & & & \\
\hline
\end{tabular}

\subsection{Normal Distribution Test}

This test was performed to validate whether the data obtained were normally distributed or not and to select the most appropriate statistical analysis to test the hypotheses of the study. The majority of parametric tests require that the data are normally distributed. To achieve this, Jarque-Bera parametric test was performed and the rule for this is to accept the null hypothesis that data are normally distributed if the probability of having a J-B test value more than $(0.05>\mathrm{a})$ (.Gujarati, 2013), and this test was performed for each variables of the study model. Table (1) shows that J-B test probability value for each study model were more than $(0.05>a)$, which indicates that the data approached the normal distribution.

\subsection{Time Series Stationary Test}

This research used the Time Series Stationary test, where it assumed that it's relatively stable. The autocorrelation may emerge in the study model due to the non- stationary time series employed in this study (AL-Shwiyat, 2013). To verify the stability of the time series, both of unit root parametric tests included in the augmented Dicky-Fuller parametric test (ADF), and the Phillips-Person (PP) non-parametric test were used as seen in table (1) shows that the absolute value for ADF parametric test and PP non- parametric test are statistically significant at the level $(0.05>a)$, which indicates that the data of the time series (2007-2016) are relatively stable.

\subsection{Multi-co-linearity Test}

The magnitude of the general linear model (GLM) depends mainly on the assumption that each of the variables is independent. If this specification is not achieved, then, the GLM model is inapplicable as this maximizes the value of $\left(\mathrm{R}^{2}\right)$, gives it more value than it intended, and makes it incapable of estimating the parameters (AlSaifo\&Meshaal, 2012). To achieve the estimation of parameters, Co-linearity diagnostics test will calculate the tolerance coefficientfor each independent variable in the study model, and then the variance inflation factor (VIF) coefficient will be calculated. Gujarati (2013) indicated that having a value of (VIF) more than (5) implies the existence of multi-co-linearity problem in data related to the designated independent variable. As seen in table (1), VIF coefficient values for all variables was more than (1) and less than (5), ranging from (1.193-4.653). Tolerance coefficient values ranges between $(0.215)$ and $(0.838)$, and this value is greater than $(0.05>a)$, which indicate that the study model doesn't include multi-co-linearity. The correlation between the study variables isn't significant and low, and this means the study model has sufficient scale in explaining the effect of the independent variables on the dependent variable.

\subsection{Autocorrelation Test}

This test verifies the absence of autocorrelation in the model of the study, which weakens the model's ability in prediction. To test this,Durbin Watson Test (DW) was performed. Hussein (2015) indicated in his study that values approaching zero indicates the existence of a statistically positive correlation among the successive residuals, while the value approaching (4) indicates the existence of a statistically negative and strong correlation. The optimal value for this test ranges between (1.5) and (2.5), indicating a non-autocorrelation between the close values of the variables (Montgomery, et al. 2001, p.216). As shown in table (1), calculated DW value for the model of the study was (2.371), which is an optimal value and indicates the study model to be free of any autocorrelations.

\subsection{Hetroskedasticity Test}

The stability of the random errors is one of the basic assumptions for the linear regression, in addition to the fact 
the means of random errors should approach zero. As for the case when the random error is not stable, some statistical methods are performed to overcome this problem, such as White Test, which is performed using eviews statistical software. This method test and solve the problem of instability concurrently. As shown in table 1 , White test probability was $(0.034)$, which is lower than $(0.05>a)$, indicating that the study model is free of any Hetroskedasticity.

\subsection{Correlation Matrix}

The regression model was tested to verify the absence of high correlations among the independent variables in the regression model (Multi-co-linearity), where such correlations makes it difficult to determine the contribution of each of the variables to explain the variance found in the dependent variable. According to Kennedy, 1985 and Anderson, et al., 1993, the existence of a correlation within the value of (70\%) or more between the two independent variables, misrepresents the relationship between one of the independent variables and the dependent variable. To verify the absence of such problem from the regression model used in this study, a correlation matrix was developed between the independent variables in the study as shown in table 2.

Table 2.

\begin{tabular}{|c|c|c|c|c|c|}
\hline Variables & $\begin{array}{l}\text { Actual } \\
\text { revenue }\end{array}$ & domestic & Actual External grants & $\begin{array}{l}\text { Current } \\
\text { Expenditure }\end{array}$ & $\begin{array}{l}\text { Capital } \\
\text { Expenditure }\end{array}$ \\
\hline Actual domestic revenue & 1 & & & & \\
\hline Actual External grants & 0.545 & & 1 & & \\
\hline Current Expenditure & $* * 0.518$ & & 0.588 & 1 & \\
\hline Capital Expenditure & $* 0.155$ & & 0.240 & 0.024 & 1 \\
\hline
\end{tabular}

*. Correlation is significant at the 0.05 level **. Correlation is significant at the 0.01 level (2-tailed).

The above table shows the correlation coefficient values between the independent variables were less than ( $70 \%)$, and this proves low correlations between the independent variables of the study, which may have negative impact on the results of the regression analysis.

\subsection{Descriptive analysis of the study variables}

Table 3 shows the results of the descriptive analysis methods for the study variables (2007-2016), such as means, standard deviations, the highest value, and the least value, and skewness and kurtosis using e-views, as follow:

-The results of the study showed that skewness values for the study variables were within the acceptable normal range for skewness coefficients, as they felled between $( \pm 1)$, ranging between $(-0.34)$ for the current expenditures and ( 0.43 ) for the capital expenditures. Kurtosis for the variables of the study were higher than the normal distribution (kurtosis $=3$ )

Table 3. Descriptive statistics of the variables

\begin{tabular}{|c|c|c|c|c|c|c|}
\hline Variable & $\begin{array}{l}\text { Actual domestic } \\
\text { revenue }\end{array}$ & $\begin{array}{l}\text { Actual } \\
\text { grants }\end{array}$ & External & $\begin{array}{l}\text { Current } \\
\text { Expenditure }\end{array}$ & Capital Expenditure & Actual disability \\
\hline Mean & 4867.09 & 693.71 & & 5575.96 & 1022.58 & 1037.53 \\
\hline Maximum & 6233.70 & 1236.53 & & 6919.30 & 1444.56 & 1824.02 \\
\hline Minimum & 3628.09 & 327.32 & & 3697.44 & 675.42 & 338.24 \\
\hline Skewness & 0.38 & 0.41 & & -0.34 & 0.43 & 0.12 \\
\hline Kurtosis & 4.71 & 4.82 & & 4.71 & 6.69 & 4.97 \\
\hline
\end{tabular}

Source: Researcher calculations depend on E-Views out put

As seen in the above table:

-Means for the total domestic revenues was (4867.09) millions, with a standard deviation of (909.62) indicating a significant variance in the actual domestic revenues in the study period. These values ranged between (3628.09) millions, representing the least value and (6233.70) millions, representing the highest value of the domestic 
revenues.

- Means for the total foreign grants during the study period was (693.71), with a standard deviation of (349.50), indicating a distribution in the foreign grants size (2007-2016), where it ranges between (327.32) representing the least value and (1236.53), representing the highest value of foreign grants.

-As for the expenditures, study results indicated an increase in the average current expenditures compared with the capital expenditures average. This is normal as the means average of current expenditures is (5575.96), while the means average of the capital expenditures is (1022.58) millions. Furthermore, there was a distribution in expenditures (2007-2016), as the expenditures size depended on the revenues size and the foreign grants.

- With respect to financial deficit average in the general budget (2007-2016), it was (1037.53) millions, which indicates that government expenditures size is higher than the government revenues. To obtain revenues, the Jordanian government relies on taxes, due to its limited natural resources. As for the increase in expenditures, it is a natural result of the increasing financial burdens, taking into consideration the significant developments in the educational, health and infrastructure services during the study period. The standard deviation was (470.43), indicating a difference in the achieved deficit value among the various years of the study period; ranging between (338.24) millions as the lowest deficit value and (1824.02) as the highest deficit value.

\subsection{Testing Hypotheses}

As long as the validity of data for statistical analysis established, and after provides the presentation of preliminary study sample, the final phase of data analysis method is now presented. As the study model addressed the relationships between various independent variables, such as actual revenues and expenditures in the Jordanian government, and the dependent variable which was the final financial report of the government (surplus/ deficit), and while the relationship between the group of independent variables and a dependent variable should be established, the most suitable regression model for such design was pooled data regression. Also, as the data analyzed in this study were cross sectional data, in addition to the fact that the study data were government general budget data within a time series of (2007-2016), and to identify the relationship between the variables of the study, e-views statistical software was employed. The following table shows the results related to study model test:

The main hypothesis of the study, which states:"There is no statistical significant relationship between the revenues size and the actual expenditures and the final report result of the Jordanian government (surplus/ deficit)".

Table 4. Test the study model

\begin{tabular}{lllll}
\hline Independent Variable & Coefficient & Expected sign & Z-Statistic & Prob. \\
\hline Actual domestic revenue & -4.467 & $+/-$ & -9.988 & 0.000 \\
Actual External grants & -0.802 & $+/-$ & -6.810 & 0.001 \\
Current Expenditure & 5.385 & $+/-$ & 9.239 & 0.000 \\
Capital Expenditure & 1.153 & $+/-$ & 4.498 & 0.006 \\
R & 0.979 & & & \\
R-squared & 0.958 & & & \\
Adjusted R Square & 0.925 & & & \\
F-statistic & 29.006 & & & \\
Prob (F-statistic) & 0.001 & & & \\
\hline
\end{tabular}

Source: Researcher calculations. Dependent variable: deficit.

The table shows a statistical significant relationship between the total revenues and expenditures variables and the government final financial report (surplus/ deficit). The correlation value was $(97.9 \%)$, which indicates a strong correlation. As for the adjusted $r$ square, it was able to explain $(0.925)$ of the variance in the dependent variable, which means that almost (92\%) of the changes in the final government financial report (surplus/ deficit) results from the changes in the revenues and expenditures in the government general budget. This is confirmed by calculated F, which was (29.006) at a significance level $(0.001)$ and this indicates the significance of the model with a statistical significant correction between the independent variables and the dependent variable.

From this main hypothesis, several sub-hypotheses were derived to measure the relationship between the actual revenues and expenditures size with the final report of the Jordanian government (surplus/ deficit). The sub- 
hypotheses of the study were tested as follows:

Testing the first sub-hypothesis stating: "There is no statistical significant relationship between the domestic revenues size and the final report of the Jordanian government (surplus/ deficit)".

As seen in the previous table, coefficient value for the domestic revenues size was (-4.467), which is a negative value indicating a negative correlation. In other words, the greater domestic revenues size, the lesser deficit in the government budget with a possibility for increasing the surplus in the budget. In another way, an increase in one point of the domestic revenues size may leads to an improvement in the Jordanian government financial report by (4.467). It also showed through testing the first hypothesis that calculated Z-Statistics amounted to $(-9.988)$, which is a significant value at $(95 \%)$ confidence level. Also, the possibility was less than $(5 \%)$ with (0.000), which means accepting the hypothesis stating: "There is a statistical significant relationship between the domestic revenues size and the final report of the Jordanian government (surplus/ deficit)".

Testing the second sub-hypothesis stating: "There is no statistical significant relationship between the actual foreign grants size and the final report of the Jordanian government (surplus/ deficit)".

As seen in the previous table, coefficient value for the foreign grants size was $(-0.802)$, which is a negative value indicating a negative correlation. In other words, the greater foreign grants size, the lesser deficit in the government budget with possibility for increasing the surplus in the budget. In another way, an increase on one point in the actual foreign grants size leads to an improvement in the Jordanian government financial report by (0.802). It also showed through testing the second hypothesis that calculated Z- Statistics amounted to (6.810), which is a significant value at $(95 \%)$ confidence level. Also, the possibility was less than $(5 \%)$ with $(0.001)$, which means accepting the hypothesis stating: "There is a statistical significant relationship between the actual foreign grants size and the final report of the Jordanian government (surplus/ deficit)".

Testing the third sub-hypothesis stating: "There is no statistical significant relationship between the actual current expenditures size and the final report of the Jordanian government (surplus/ deficit)".

As seen in the previous table, coefficient value for the current expenditures size was (5.385), which is a positive value indicating a positive correlation. In another word, the greater current expenditures size, the greater deficit in the government budget with possibility for reducing the surplus in the budget. It another way, an increase in one point of the current expenditures size leads to an increase in the government deficit in the Jordanian government financial report by (5.385). It also showed through testing the third hypothesis that calculated Z-Statistics amounted to (9.239), which is a significant value at (95\%) confidence level. Also, the possibility was less than $(5 \%)$ with $(0.000)$, which means accepting the hypothesis stating: "There is a statistical significant relationship between the current expenditures size and the final report of the Jordanian government (surplus/ deficit)".

Finally, testing the fourth sub-hypothesis stating: "There is no statistical significant relationship between the actual capital expenditures size and the final report of the Jordanian government (surplus/ deficit)".

As seen in the previous table, coefficient value for the capital expenditures size was (1.153), which is a positive value indicating a positive correlation. In other words, the greater capital expenditures size, the greater deficit in the government budget with the possibility for reducing the surplus in the budget. In another way, an increase in one point of the capital expenditures size leads to an increase in the government deficit in the Jordanian government financial report by (1.153). It also showed through testing the third hypothesis that calculated Z-Statistics amounted to (4.498), which is a significant value at (95\%) confidence level. Also, the possibility was less than $(5 \%)$ at $(0.006)$, which means accepting the hypothesis stating: "There is a statistical significant relationship between the capital expenditures size and the final report of the Jordanian government (surplus/ deficit)".

\section{Results and Recommendations}

\subsection{Results}

The most significant results obtained from this study may be summarized in the following:

-There was a statistical significant correlation between the actual revenues and expenditures size variables as a whole and the government final financial report (surplus/ deficit).

-There was a statistical significant reverse correlation between the actual revenues and expenditures size and the government final financial report (surplus/ deficit). The greater domestic revenues, the lesser the deficit in the government budget with greater surplus.

-There was a statistical significant positive correlation between the actual current expenditures size and the 
government final financial report (surplus/ deficit). The greater current expenditures, the greater the deficit in the government budget with lesser surplus.

- There was a statistical significant positive correlation between the actual capital expenditures size and the government final financial report (surplus/ deficit). The greater capital expenditures, the greater deficit in the government budget with lesser surplus.

\subsection{Recommendations}

The most significant recommendations obtained from this study may be summarized in the following:

-Develop internal and external auditing to correctly collect the revenues due.

-Deposit all foreign grants in the general budget to be subject for auditing.

-Develop the necessary procedures in the internal and external auditing to control waste in the currentexpenditures and to improve the outcomes of the capital expenditures.

- Adopt the financial policies that aim to achieve the highest revenues and to prevent tax avoidance.

-There is a need to apply this study in Government units independent of the general public such as universities and local government.

\section{References}

Abu Al-Soundus, J. A., \& Al Louzi, S. A. (2011). Analyzing the gap in estimated and actual general budget in Hashemite kingdom of Jordan (1996-2006). Economic Horizons, 32(119), 63-92.

Al Saifo, W. I., \& Meshaal, A. M. (2012). The analytical measurement economy: Theory and practice (3rd ed.). Majdalawi Publishing, Amman-Jordan.

Al Sharaa, M. K., \& Al Edwan, K. I. (2014). The Political Dimensions of the State's General Budget. Dirasat: Human and Social Sciences, 41(3), 784-802.

Al-Khulaifi, A. S. (2012). The relationship between government revenue and expenditure in Qatar: a cointegration and causality investigation. International Journal of Economics and Finance, 4(9), 142. http://dx.doi.org/10.5539/ijef.v4n9p142

AL-Shwiyat, Z. M. M., ALRjoub, A. M. S., \& Bshayreh, M. M. (2013). The impact of Social Responsibility on the Financial Performance for Jordanian Companies (Case Study-Service Sector). European Journal of Business and Management, 5(30), 123-133.

Anderson, D. R., Sweeney, D. R., \& Williams, T. A. (1993). Statistics for Business and Economics (5th ed.). West Publishing Company, St. Paul, MN.

Code of general budget organization, no. 58, published in 2008.

Farshad, \& Keivani, S. (2013). The Relationship between the Government Expenditures and Revenues in the Long Run: A Case Study of Iran. IOSR Journal of Business and Management (IOSR-JBM), 14(6).

Gujarati, D. N. (2013). Basic Econometrics (7th ed.). McGraw-Hill.

Hussein, H. B. (2015). Data analysis using SPSS (1st ed.). Dar Wael Publishing's, Amman, Jordan.

Kennedy, P. (1985). A Guide to Econometrics (2nd ed.). Basil Blackwell Ltd, Oxford.

Kraan, D. J., Bergvall, D., \& Hawkesworth, I. (2007). Budgeting in Turkey. OECD Journal on Budgeting, 7(2), 7-58.

Lojanica, N. (2015). Government Expenditure and Government Revenue: The Causality on the Example of the Republic of Serbia. In MIC 2015: Managing Sustainable Growth; Proceedings of the Joint International Conference, Portorož, Slovenia, 28-30 May 2015 (pp. 79-90). University of Primorska, Faculty of Management Koper.

Mehrara, M., \& Rezaei, A. A. (2014). The Relationship between Government Revenue and Government Expenditure in Iran. International Journal of Academic Research in Business and Social Sciences, 4(3), 171. https://doi.org/10.6007/IJARBSS/v4-i3/687

Montgomery, D. C., Peck, E. A, \& Vining, G. G, (2001). Introduction to Liner Regression Analysis (3th ed.). New York, NY, John Wiley \& Sons.

Nwosu, D. C., \& Okafor, H. O. (2014). Government revenue and expenditure in Nigeria: A disaggregated analysis. Asian Economic and Financial Review, 4(7), 877. 
Odionye, J. C., \& Uma, K. E. (2013). The relationship between budget deficit and interest rate: evidence from Nigeria. European Journal of Business and Social Sciences, 2(1), 158-167.

Petanlar, S. K., \& Sadeghi, S. (2012). Relationship between government spending and revenue: Evidence from oil exporting countries. International Journal of Economics and Management Engineering, 2(2), 95-77.

Ullah, N. (2016). The Relationship of Government Revenue and Government Expenditure: A case study of Malaysia.

\section{Copyrights}

Copyright for this article is retained by the author(s), with first publication rights granted to the journal.

This is an open-access article distributed under the terms and conditions of the Creative Commons Attribution license (http://creativecommons.org/licenses/by/4.0/). 